\title{
Long-Term Mortality of Coronary Artery Bypass Graft Surgery and Bare-Metal Stenting
}

\author{
Chuntao Wu, MD, PhD ${ }^{1}$, Songyang Zhao, $\mathrm{MS}^{2}$, Andrew S. Wechsler, MD ${ }^{3}$, Stephen Lahey, \\ $M^{4}$, Gary Walford, MD ${ }^{5}$, Alfred T. Culliford, MD $^{6}$, Jeffrey P. Gold, MD ${ }^{7}$, Craig R. Smith, \\ MD $^{8}$, David R. Holmes Jr, MD ${ }^{9}$, Spencer B. King III, MD ${ }^{10}$, Robert S.D. Higgins, MD ${ }^{11}$, \\ Desmond Jordan, MD ${ }^{12}$, and Edward L. Hannan, PhD $^{2}$ \\ ${ }^{1}$ Department of Public Health Sciences, Penn State Hershey College of Medicine, Hershey PA \\ ${ }^{2}$ School of Public Health, University at Albany, State University of New York, Rensselaer, NY \\ ${ }^{3}$ Department of Cardiothoracic Surgery, Drexel University College of Medicine, Philadelphia, PA \\ ${ }^{4}$ Division Cardiothoracic Surgery, Maimonides Medical Center, Brooklyn, NY \\ ${ }^{5}$ Heart and Vascular Institute, Johns Hopkins Medical Center, Baltimore, MD \\ ${ }^{6}$ Department of Cardiothoracic Surgery, New York University Medical Center, New York, NY \\ ${ }^{7}$ College of Medicine, University of Toledo, Toledo, $\mathrm{OH}$ \\ ${ }^{8}$ Department of Surgery, Columbia University, New York, NY \\ ${ }^{9}$ Cardiac Catheterization Laboratory, Mayo Clinic, Rochester, MN \\ ${ }^{10}$ St. Joseph's Health System, Atlanta, GA \\ ${ }^{11}$ Division of Cardiac Surgery, Ohio State University, Columbus, $\mathrm{OH}$ \\ ${ }^{12}$ Department of Anesthesiology, Columbia University, New York, NY
}

\begin{abstract}
Background-There is little information on the relative survival of coronary artery bypass graft (CABG) surgery and percutaneous coronary intervention with stenting with follow-up longer than 5 years. This study tested the hypothesis that CABG surgery is associated with lower risk of longterm (8-year) mortality than stenting with bare-metal stents for multivessel coronary disease.
\end{abstract}

Methods-We identified 18,359 patients with multivessel disease who underwent isolated CABG surgery and 13,377 patients who received BMS in 1999-2000 in New York, and followed their vital status through 2007 using the National Death Index. We matched CABG and stent patients on the number of diseased coronary vessels, proximal left anterior descending (LAD) artery disease, and propensity of undergoing $\mathrm{CABG}$ surgery based on numerous patient characteristics, and compared the survival after the two procedures.

\footnotetext{
(C) 2011 The Society of Thoracic Surgeons. Published by Elsevier Inc. All rights reserved.

Corresponding Author: Chuntao Wu, MD, PhD, Penn State Hershey College of Medicine, 600 Centerview Dr., ASB 2200, A210, Hershey, PA 17033, chuntao.wu@psu.edu, Tel: 717-531-4209, Fax: 717-531-5779.

Publisher's Disclaimer: This is a PDF file of an unedited manuscript that has been accepted for publication. As a service to our customers we are providing this early version of the manuscript. The manuscript will undergo copyediting, typesetting, and review of the resulting proof before it is published in its final citable form. Please note that during the production process errors may be discovered which could affect the content, and all legal disclaimers that apply to the journal pertain.

Disclosures and Freedom of Investigation: The authors had full control of the design of the study, methods used, outcome parameters and results, analysis of data and production of the written report. The views expressed are those of the authors and do not necessarily reflect those of the New York State Department of Health.
} 
Results-In the 7,235 pairs of matched patients, the overall 8-year survival rates were $78.0 \%$ for CABG surgery and $71.2 \%$ for stenting (hazard ratio $=0.68,95 \%$ confidence interval: 0.64 to 0.74 , $\mathrm{P}<0.001)$. For anatomic groups classified by the number of diseased vessels and proximal LAD involvement, the hazard ratios ranged from $0.53(\mathrm{P}<0.001)$ for patients with 3 -vessel disease involving proximal LAD artery disease to $0.78(\mathrm{P}=0.05)$ for patients with 2-vessel disease but no disease in the LAD artery. A lower risk of death after CABG surgery was observed in all subgroups stratified by a number of baseline risk factors.

Conclusions-CABG surgery is associated with lower risk of death than stenting with baremetal stents for multivessel coronary disease.

\section{Keywords}

Coronary artery bypass grafts; Coronary percutaneous interventions; Outcomes

\section{INTRODUCTION}

The debate on the relative benefit of coronary artery bypass graft (CABG) surgery and percutaneous coronary intervention (PCI) is still ongoing although a number of randomized clinical trials (RCTs) [1-5] and observational studies[6-10] have compared these 2 procedures. With respect to long-term survival, most of the RCTs reported no overall differences between the 2 procedures, but most of the observational studies reported a lower risk of death for CABG surgery[11-13].

In current clinical practice, the majority of the PCI procedures involve stenting. However, there are little data on the relative survival of CABG surgery and stenting for follow-up periods longer than 5 years. Given the risk of possible long-term graft failure, especially for saphenous vein grafts used for CABG surgery[14], there is a need to examine the longerterm risk of death following $\mathrm{CABG}$ surgery and stenting.

Although drug-eluting stents (DES) were approved several years ago, bare-metal stents (BMS) are still commonly used. Austin and colleagues reported that in 2007 BMS were used in 68\% of stented lesions in Belgium, 63\% in Alberta, Canada, 58\% in Scotland, U.K., and 25\% in the Mayo Clinic in the U.S.[15]. The most recent data of the American College of Cardiology/National Cardiovascular Data Registry showed that BMS accounted for $24 \%$ of all stents implanted in the $2^{\text {nd }}$ quarter of 2009[16]. Therefore, in this study, we tested the hypothesis that $\mathrm{CABG}$ surgery is associated with decreased risk of long-term (8-year) mortality compared to stenting with BMS for patients with multivessel coronary disease.

\section{PATIENTS AND METHODS}

\section{Databases}

This study used secondary data and was approved by the Institutional Review Boards at University at Albany and Penn State Hershey. The study population was identified using the databases from New York State's Cardiac Surgery Reporting System (CSRS) and Percutaneous Coronary Intervention Reporting System (PCIRS). The CSRS was initiated in 1989 to register all cardiac surgery cases operated in non-federal hospitals in New York State; and the PCIRS was established in 1991 to register all PCI cases. In each database, variables such as patient demographics; dates of admission, procedure, and discharges; coronary vessels diseased; ejection fraction; history of revascularization procedures; myocardial infarction (MI); hemodynamic stability; a number of comorbidities; types of procedures; post-procedural complications; and discharge status are collected. Regarding types of procedures, the CSRS contains primary and secondary cardiac procedures and the 
PCIRS contains the types of devices used. The databases are periodically matched to the New York State's hospital discharge database to ensure that all PCIs and cardiac surgery procedures are reported by hospitals. The accuracy of risk factor reporting is monitored by the New York State Department of Health's utilization review agent through sampling patients' medical records.

The vital status of patients after the index admission for CABG surgery or stenting was followed using the National Death Index (NDI). The NDI is a nationwide database managed by the National Center for Health Statistics, and it captures all death records in the United States. The patients in this study were matched to NDI using patients' social security numbers, sex, and date of birth.

\section{Study Population}

The CSRS and PCIRS databases were used to identify patients who underwent isolated CABG surgery (without other major cardiac procedures) or stenting with BMS in New York State in 1999 and 2000. The patient selection criteria included (1) patients who had multivessel coronary disease, defined as stenosis of at least $70 \%$ in at least 2 of the 3 major epicardial arteries, (2) no left main coronary artery disease defined by the presence of stenosis of at least $50 \%$, (3) no history of coronary revascularization prior to the index procedures, (4) no acute myocardial infarction (AMI) within 24 hours prior to the index procedure. A total of 18,359 CABG patients and 13,377 stenting patients were identified based on the selection criteria and were included in this study.

\section{End Point}

The end point of the study was mortality after the index CABG or stenting procedure. The NDI was used to track each patient's vital status through December 31, 2007. The median length of follow-up for the study population from the date of procedure to the end of 2007 was 8.0 years.

\section{Statistical Analysis}

Bivariate analyses were conducted to compare the distributions of pre-procedural risk factors between the CABG and stent patients. The Student's t-test was used for continuous variables, and Pearson's chi-square test was used for categorical variables.

To control for possible treatment selection bias, propensity-score matching [17] was used to balance the distributions of baseline risk factors between the CABG and BMS patients. Because the number of diseased vessels and the presence/absence of proximal LAD disease were regarded as extremely important factors, $\mathrm{CABG}$ and stent patients were matched exactly on these factors. Matching for other important risk factors was obtained by developing a propensity score. To obtain the propensity score, i.e., the log-odds of the probability of receiving CABG surgery, all available risk factors were included as independent variables in a logistic (propensity) model that predicted the probability of receiving $\mathrm{CABG}$ surgery rather than $\mathrm{BMS}$. The $\mathrm{CABG}$ and $\mathrm{BMS}$ patients were then matched to each other using a 1:1 ratio on the number of diseased vessels, the presence of proximal left anterior descending (LAD) artery disease, and the value of a propensity score. The propensity-matching caliper was 0.1 times the standard deviation of the propensity score. The standardized differences of the prevalences of risk factors between the matched CABG and stenting patients were then examined to determine whether the risk factors were well balanced after matching[18].

The overall difference in survival between CABG surgery and stenting was examined by comparing Kaplan-Meier survival curves for the matched patients[18, 19]. The difference in 
survival between the 2 treatment groups was further examined for each anatomic group defined by the number of diseased coronary vessels and the presence/absence of proximal LAD artery disease. The 5 anatomic groups were (1) three-diseased vessels with diseased proximal LAD artery, (2) three diseased vessels with diseased nonproximal LAD artery, (3) two diseased vessels with diseased proximal LAD artery, (4) two diseased vessels with diseased nonproximal LAD artery, and (5) two diseased vessels without diseased LAD artery.

The overall hazard ratio for death after CABG surgery and stenting was obtained by fitting a Cox proportional hazards model stratifying on the matched pairs of patients.[18] To assess whether the relative risk of death following CABG surgery and stenting was dependent on the number of diseased vessels and the involvement of LAD artery, the significance of the interaction terms between type of treatment and diseased vessels was tested by including treatment (CABG surgery or stenting), variables representing anatomic groups, and their interaction terms in a Cox proportional hazards model.

In addition, interactions between treatment type and a number of other baseline risk factors such as age, sex, ejection fraction, history of MI, and various comorbidities were tested. For each risk factor of interest, a Cox proportional hazards model was fit including treatment, the risk factor being examined, and their interaction while adjusting for significant $(\mathrm{P}<0.05)$ risk factors for death selected by a backwards selection approach.

All statistical analyses were conducted in SAS version 9.1 (SAS Institute, Cary, NC).

\section{RESULTS}

Compared to the BMS patients ( $\mathrm{n}=13,377)$, CABG patients $(\mathrm{n}=18,359)$ were slightly older, were more likely to be male, non-Hispanic white, have three vessel disease, have lower ejection fractions, have a history of AMI, be hemodynamically unstable or in shock, and have a number of comorbidities including cerebrovascular disease, peripheral arterial disease, left ventricular hypertrophy, congestive heart failure, chronic obstructive pulmonary disease, diabetes, and renal failure.

The propensity matching yielded 7,235 pairs of CABG and stent patients matched on the number of diseased vessels, the presence of proximal or nonproximal LAD artery, and propensity scores. The $\mathrm{C}$ statistic for the propensity model was 0.847 . Table 1 shows that the standardized differences in the prevalence of all baseline risk factors between the CABG and stenting patients were all $\leq 2.2 \%$ and were not statistically significant.

During the follow-up period through 2007, 1,584 deaths were observed among the 7,235 paired-matched CABG patients, and 2,074 deaths were observed among the 7,235 matched stent patients. Figure 1-A shows that the overall 8-year survival rate was higher for CABG surgery than stenting $(78.0 \%$ vs. $71.2 \%, \mathrm{P}<0.001)$. Table 3 shows that the risk of death for CABG surgery was $32 \%$ lower than for stenting (hazard ratio (HR) $=0.68,95 \%$ CI: $0.64-$ $0.74, \mathrm{P}<0.001)$.

Figures $1 \mathrm{~B}$ through $1 \mathrm{~F}$ show that the differences in 8-year survival rates between $\mathrm{CABG}$ surgery and stenting were highly significant for all anatomic subgroups (all $\mathrm{P}$ values were $\leq$ 0.002 ) except for the group of patients with 2 diseased vessels without LAD artery disease possibly due to small sample size ( $75.1 \%$ vs. $70.1 \%, \mathrm{P}=0.05)$. The differences in 8 -year survival rates between CABG surgery and stenting ranged from $12.9 \%$ for 3-vessel disease involving proximal LAD artery disease $(77.3 \%$ vs. $64.4 \%, \mathrm{P}<0.001)$ to $3.6 \%$ for 2 -vessel disease with proximal LAD artery disease $(79.6 \%$ vs. $76.0 \%, \mathrm{P}<0.001)$. Table 3 shows that the HR ranged from 0.53 (95\% CI: $0.45-0.63, \mathrm{P}<0.001)$ for patients with 3 -vessel disease 
involving proximal LAD artery disease to 0.78 (95\% CI: $0.62-1.00, \mathrm{P}=0.05)$ for 2-vessel disease without LAD artery disease. The interaction between treatment and anatomic groups was significant $(\mathrm{P}=0.004)$, indicating that there were significant differences in the sizes of HRs across subgroups though the HRs were consistently lower than 1 in all anatomic groups (Table 3).

Table 3 shows that the 8-year survival rates for CABG surgery were significantly higher than stenting in all subgroups of patients classified by age, sex, ejection fraction, history of MI, and presence of cerebrovascular disease, peripheral artery disease, congestive heart failure, and diabetes. Risk-adjusted mortality following CABG surgery was significantly lower than for BMS across all subgroups, with the adjusted HRs ranging from 0.54 to 0.75 (all $\mathrm{P}$ values $<0.05$ ). The interaction term for treatment with history of MI was statistically significant $(\mathrm{P}=0.03)$, suggesting that the reduction in the risk of death for $\mathrm{CABG}$ surgery was greater for the patients with a history of MI than without previous MI (adjusted HRs, 0.58 vs. 0.75 ). The interaction terms for treatment with other risk factors examined in Table 3 were not statistically significant, meaning that the relative risks of death following CABG surgery and stenting were not different between patients of different ages, between male and female, of different ejection fraction values, and between patients with and without comorbidities such as cerebrovascular disease, peripheral artery disease, congestive heart failure, and diabetes.

\section{COMMENT}

In this study, we found that CABG surgery was associated with lower risk of risk of death compared to stenting, and the survival advantage for CABG surgery was consistent across patient subgroups. The findings are consistent with other multi-center observational studies that compared CABG surgery and PCI in the BMS era $[8,9]$, in which at least $60 \%$ of the PCI cases received BMS. However, our finding is different from the 3 of the 4 major randomized trials comparing CABG surgery and PCI stenting for multivessel coronary disease in the BMS era (the Arterial Revascularization Therapies Study (ARTS)[2], the Argentine Randomized Trial of Coronary Angioplasty with Stenting Versus Coronary Bypass Surgery (ERACI II)[3], the Medicine, Angioplasty, or Surgery Study (MASS II)[4], and the Stent or Surgery (SOS) Trial[5]). There was no difference in survival following the 2 procedures in ARTS[2], ERACI II[3], or MASS II[4]. However, similar to our findings, the SOS trial reported a significant survival advantage for CABG surgery $(\mathrm{HR}=0.60,95 \%$ CI: $1.08-2.55, \mathrm{P}=0.02)$ [5]. It is worth noting that the SOS trial was a practical trial, unlike the other 3 trials. In SOS, optimum coronary revascularization was performed according to the best local practice to patients who were considered suitable for both CABG surgery and PCI. In addition, the SOS trial had less restriction on patient enrollment, and no restriction on anesthesia, equipment, technique, or adjunctive medication schedules[5]. Therefore, despite the fact that the SOS is a randomized study, the peri-procedural management resembles what happens in real-world practice from which our data were collected. This similarity may partially account for the fact that our finding is similar to the SOS trial[5], but different from the other trials[2-4].

When comparing CABG surgery and stenting across anatomic groups defined by diseased vessels, we found that the survival advantage for CABG surgery existed for both 2-and 3vessel disease. The Bair et al. study reported similar findings[9], but the Malenka et al. study found that the reduced risk of death for CABG surgery was limited to 3-vessel disease[8]. However, the Malenka study did show a trend towards lower risk of death for CABG surgery in patients who had 2-vessel disease with a diseased proximal LAD artery (adjusted $\mathrm{HR}=0.89, \mathrm{P}=0.55$ ). Unlike the observational studies, a meta-analysis[13] of the 4 RCTs comparing $\mathrm{CABG}$ surgery and stenting with BMS reported there was no difference in risk of 
death between the 2 procedures, consistent with the null findings in most individual $\operatorname{RCTs}[2-4]$.

Our study also found that the decreased risk of death following CABG surgery was present in patient subgroups defined by age, sex, ejection fraction, history of MI, and the presence of cerebrovascular disease, peripheral artery disease, congestive heart failure, and diabetes.

Bair and colleagues also reported that there was a trend favoring CABG surgery in subgroups stratified by age, sex, ejection fraction, history of MI, congestive heart failure, and diabetes[9]. Malenka and colleagues reported a similar trend for 3-vessel disease in subgroups stratified by age, sex, ejection fraction, and diabetes, but not for 2-vessel disease[8]. However, the meta-analysis by Daemen and colleagues found no difference in mortality after the 2 procedures in subgroups stratified by age, sex, ejection fraction, history of MI, peripheral vascular disease, or diabetes[13]. In a pooled analysis including the RCTs in both the BMS and balloon angioplasty eras that showed no overall difference in morality following CABG surgery and PCI, Hlatky and colleagues found a significantly decreased risk of mortality after CABG in patients who were at least 65 years old or had diabetes[12]. However, unlike our findings, they found no differences in mortality between the 2 procedures in subgroups stratified by sex, ejection fraction, history of MI, peripheral vascular disease, or heart failure[12]. It is worth emphasizing that the survival advantage following CABG surgery in diabetes was consistently observed in our study as well as other observational studies [8,9] and the pooled analysis of RCTs[12].

There are few caveats in this study. First, as an observational study, treatment selection bias may affect the validity of study. We conducted a propensity-matched analysis to best minimize this potential bias by balancing the distribution of baseline risk factors between the 2 treatment groups. However, we did not have the data to examine appropriateness and preference for a given procedure. Nonetheless, observational studies do provide an opportunity to evaluate the comparative effectiveness of these 2 procedures in a real-world setting. Second, this study included only BMS cases. However, despite the fact that drugeluting stents are adopted widely, BMS are still used in $25 \%$ of the stented lesions in the U.S. [16] and more than $60 \%$ in Canada and the Europe[15]. It is possible that the BMS patients in the current practice may have more severe coronary disease and more comorbidities than their DES counterparts and their BMS counterparts in the study period (1999-2000). Therefore, caution should be applied when generalizing the results of this study to current practice. However, the validity of this study is ensured as much as possible by using propensity-matched analysis that included many baseline risk factors that represent patients' severity of disease.

In conclusion, we found that $\mathrm{CABG}$ surgery was associated with lower risk of death compared to stenting with BMS for multivessel coronary disease. This finding can be used by clinicians and patients to make informed clinical decisions when treating severe coronary artery disease.

\section{Acknowledgments}

This work was supported by the National Institutes of Health (RC1HL099122). We thank the New York State Cardiac Advisory Committee for their encouragement and support of this study; and Kimberly Cozzens, Cynthia Johnson, Rosemary Lombardo, and the cardiac catheterization laboratories and cardiac surgery programs of the participating hospitals for their tireless efforts to ensure the timeliness, completeness, and accuracy of the registry data. 


\section{References}

1. Serruys PW, Morice M-C, Kappetein AP, et al. Percutaneous coronary intervention versus coronaryartery bypass grafting for severe coronary artery disease. New England Journal of Medicine. 2009; 360:961-972. [PubMed: 19228612]

2. Serruys PW, Ong ATL, van Herwerden LA, et al. Five-year outcomes after coronary stenting versus bypass surgery for the treatment of multivessel disease - The final analysis of the arterial revascularization therapies study (ARTS) randomized trial. Journal of the American College of Cardiology. 2005; 46:575-581. [PubMed: 16098418]

3. Rodriguez AE, Baldi J, Pereira CF, et al. Five-year follow-up of the argentine randomized trial of coronary angioplasty with stenting versus coronary bypass surgery in patients with multiple vessel disease (ERACI II). Journal of the American College of Cardiology. 2005; 46:582-588. [PubMed: 16098419]

4. Hueb W, Lopes N, Gersh BJ, et al. Ten-year follow-up survival of the Medicine, Angioplasty, or Surgery Study (MASS II) A randomized controlled clinical trial of 3 therapeutic strategies for multivessel coronary artery disease. Circulation. 2010; 122:949-957. [PubMed: 20733102]

5. Booth J, Clayton T, Pepper J, et al. Randomized, controlled trial of coronary artery bypass surgery versus percutaneous coronary intervention in patients with multivessel coronary artery disease - Sixyear follow-up from the stent or surgery trial (SoS). Circulation. 2008; 118:381-388. [PubMed: 18606919]

6. Hannan EL, Racz MJ, Walford G, et al. Long-term outcomes of coronary-artery bypass grafting versus stent implantation. New England Journal of Medicine. 2005; 352:2174-2183. [PubMed: 15917382]

7. Hannan EL, Wu CT, Walford G, et al. Drug-eluting stents vs. coronary-artery bypass grafting in multivessel coronary disease. New England Journal of Medicine. 2008; 358:331-341. [PubMed: 18216353]

8. Malenka DJ, Leavitt BJ, Hearne MJ, et al. Comparing long-term survival of patients with multivessel coronary disease after CABG or PCI - Analysis of BARI-like patients in northern New England. Circulation. 2005; 112:I371-I376. [PubMed: 16159849]

9. Bair TL, Muhlestein JB, May HT, et al. Surgical Revascularization is associated with improved long-term outcomes compared with percutaneous stenting in most subgroups of patients with multivessel coronary artery disease - Results from the intermountain heart registry. Circulation. 2007; 116:I226-I231. [PubMed: 17846308]

10. Javaid A, Steinberg DH, Buch AN, et al. Outcomes of coronary artery bypass grafting versus percutaneous coronary intervention with drug-eluting Stents for patients with multivessel coronary artery disease. Circulation. 2007; 116:I200-I216. [PubMed: 17846304]

11. Bravata DM, Gienger AL, McDonald KM, et al. Systematic review: The comparative effectiveness of percutaneous coronary interventions and coronary artery bypass graft surgery. Annals of Internal Medicine. 2007; 147:703-716. [PubMed: 17938385]

12. Hlatky MA, Boothroyd DB, Bravata DM, et al. Coronary artery bypass surgery compared with percutaneous coronary interventions for multivessel disease: a collaborative analysis of individual patient data from ten randomised trials. Lancet. 2009; 373:1190-1197. [PubMed: 19303634]

13. Daemen J, Boersma E, Flather M, et al. Long-term safety and efficacy of percutaneous coronary intervention with stenting and coronary artery bypass surgery for multivessel coronary artery disease: a meta-analysis with 5-year patient-level data from the ARTS, ERACI-II, MASS-II, and SoS trials. Circulation. 2008; 118:1146-1154. [PubMed: 18725490]

14. Goldman S, Zadina K, Moritz T, et al. Long-term patency of saphenous vein and left internal mammary artery grafts after coronary artery bypass surgery: Results from a Department of Veterans Affairs Cooperative Study. J Am Coll Cardiol. 2004; 44:2149-2156. [PubMed: 15582312]

15. Austin D, Oldroyd KG, Holmes DR, et al. Drug-eluting stents: A study of international practice. American Heart Journal. 2009; 158:576-584. [PubMed: 19781417]

16. Krone RJ, Rao SV, Dai D, et al. Acceptance, panic, and partial recovery the pattern of usage of drug-eluting stents after introduction in the U.S. (a report from the American College of 
Cardiology/National Cardiovascular Data Registry). JACC Cardiovasc Interv. 2010; 3:902-910. [PubMed: 20850088]

17. Rosenbaum PR, Rubin DB. The central role of the propensity score in observational studies for causal effects. Biometrika. 1983; 70:41-55.

18. Austin PC. Propensity-score matching in the cardiovascular surgery literature from 2004 to 2006: a systematic review and suggestions for improvement. J Thorac Cardiovasc Surg. 2007; 134:11281135. [PubMed: 17976439]

19. Klein, JP.; Moeschberger, ML. Survival Analysis: Techniques for Censored and Truncated Data. 2nd ed.. New York, NY: Springer; 2003. p. 201-242. 


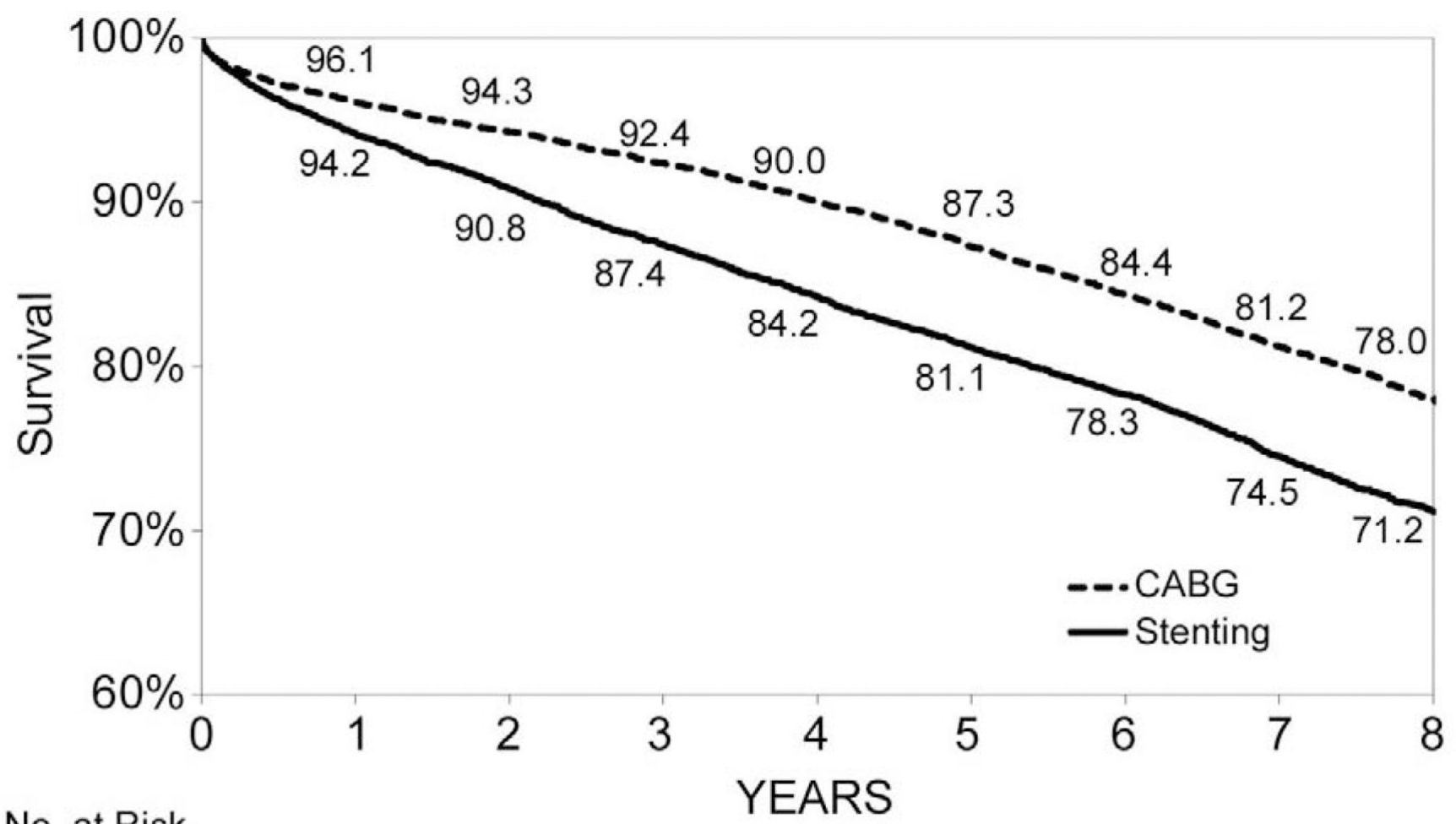

No. at Risk

$\begin{array}{lrrrrrrrrr}\text { CABG } & 7235 & 6952 & 6820 & 6683 & 6510 & 6315 & 6103 & 5875 & 2833 \\ \text { Stenting } & 7235 & 6812 & 6571 & 6321 & 6094 & 5870 & 5663 & 5391 & 2451 \\ \text { P Value } & <0.001 & <0.001 & <0.001 & <0.001 & <0.001 & <0.001 & <0.001 & <0.001\end{array}$




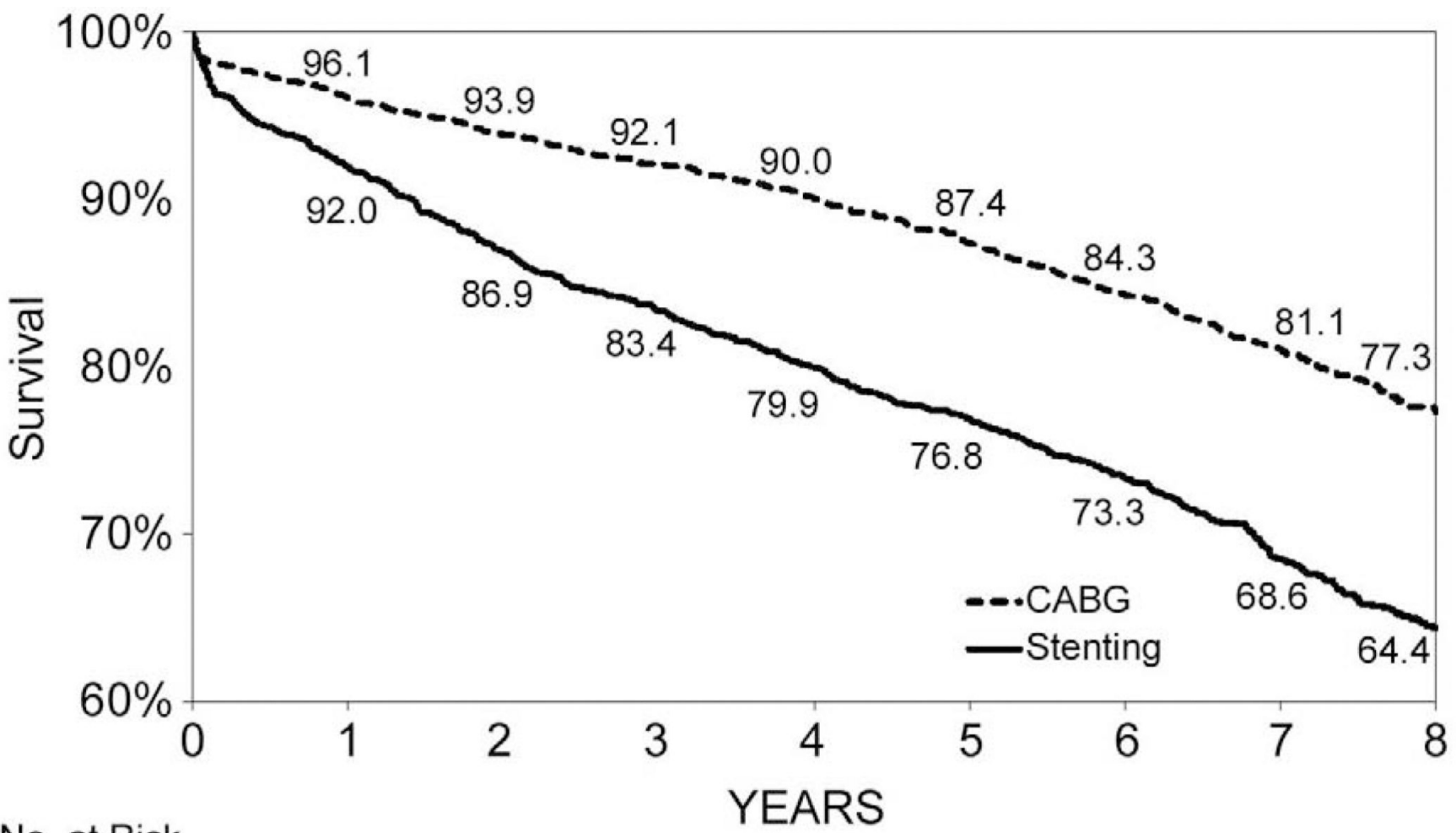

No. at Risk

$\begin{array}{lrrrrrrrrr}\text { CABG } & 1346 & 1293 & 1264 & 1240 & 1212 & 1176 & 1134 & 1091 & 506 \\ \text { Stenting } & 1346 & 1293 & 1169 & 1122 & 1076 & 1034 & 987 & 923 & 412 \\ \text { P Value } & <0.001 & <0.001 & <0.001 & <0.001 & <0.001 & <0.001 & <0.001 & <0.001\end{array}$




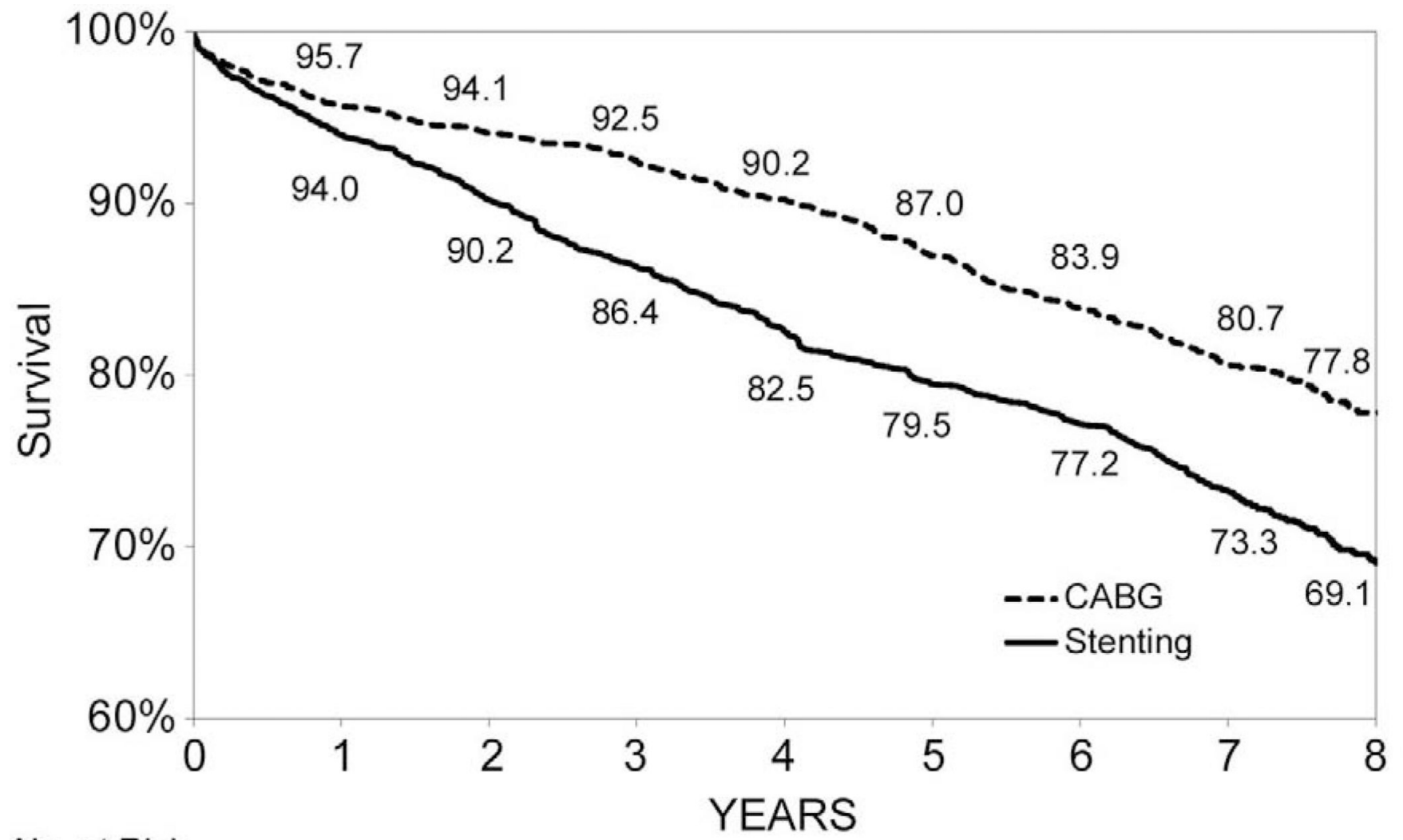

No. at Risk

CABG 1392

1332

$1310 \quad 1287$

1256

1211

$1168 \quad 1123$

538

Stenting 1392

1309

$1256 \quad 1202$

1149

1107

1074

1020

445

$\mathrm{P}$ Value

0.02

$<0.001<0.001$

$<0.001<0.001$

$<0.00$ 


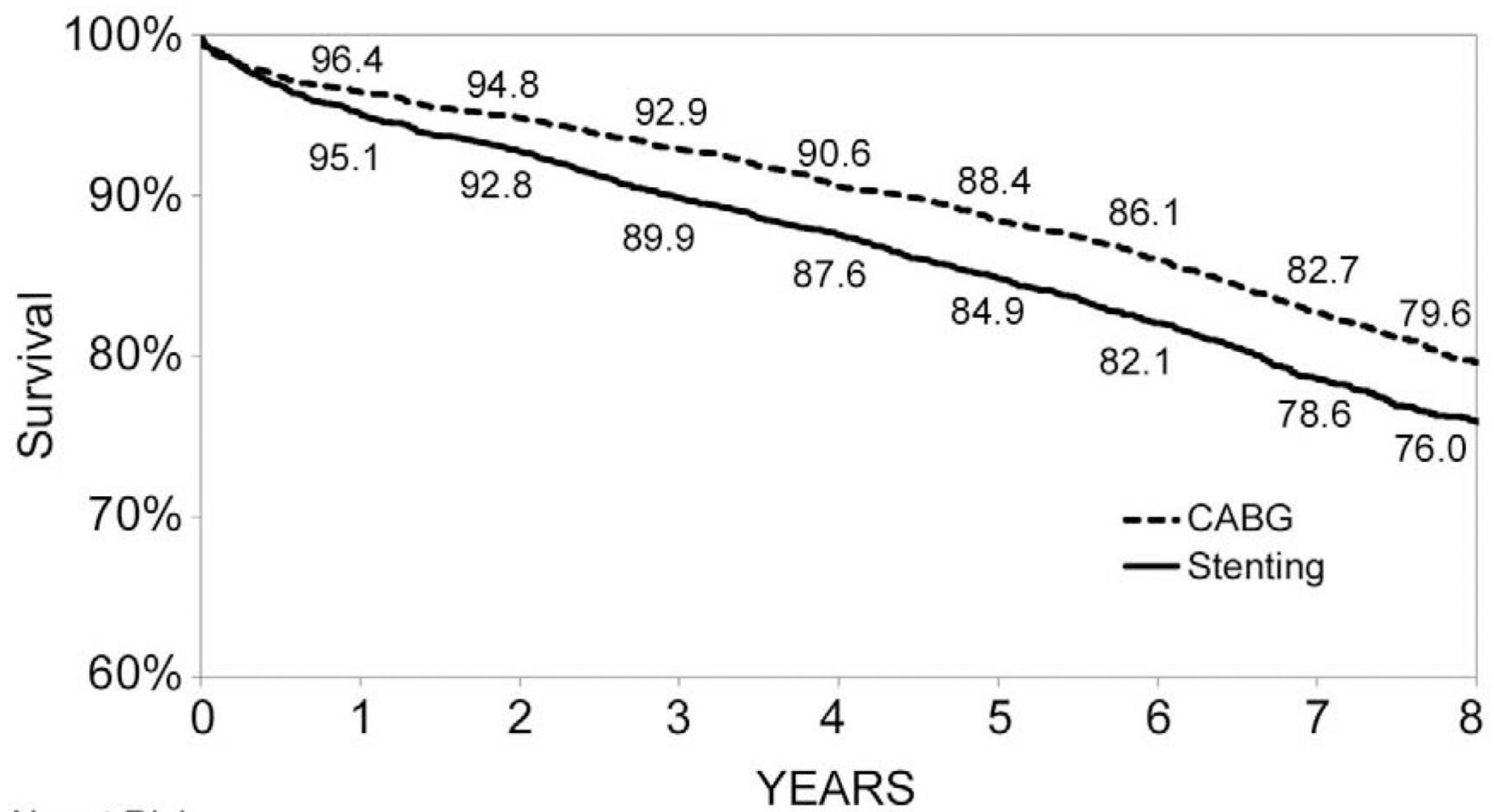

No. at Risk

$\begin{array}{llllllllll}\text { CABG } & 2974 & 2868 & 2820 & 2764 & 2694 & 2630 & 2560 & 2459 & 1215\end{array}$ $\begin{array}{lllllllll}\text { Stenting } 2974 & 2829 & 2759 & 2672 & 2694 & 2524 & 2441 & 2337 & 1076\end{array}$

$\begin{array}{llllllll}P \text { Value } & 0.02 & 0.002 & <0.001 & <0.001<0.001<0.001<0.001<0.001\end{array}$ 


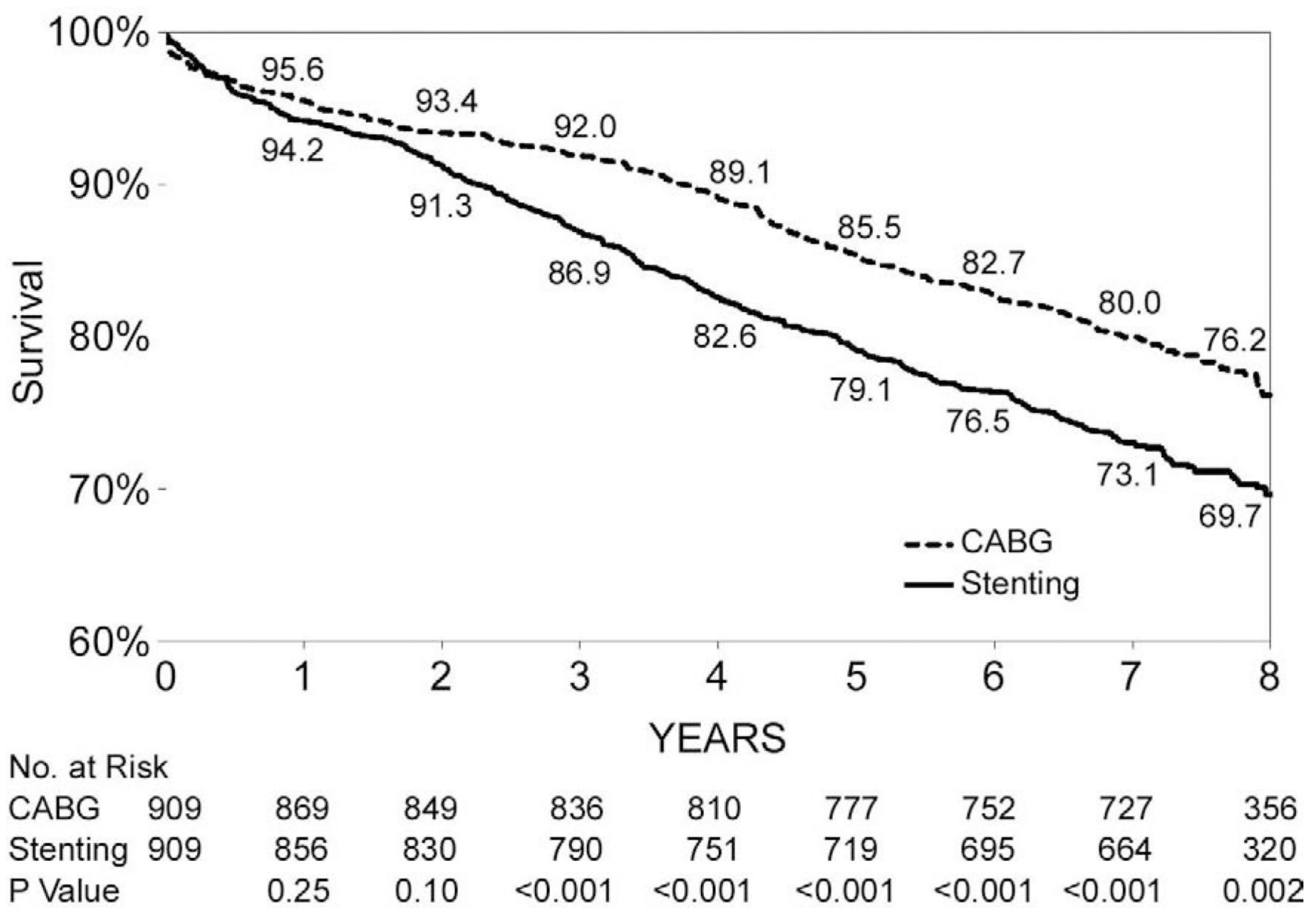




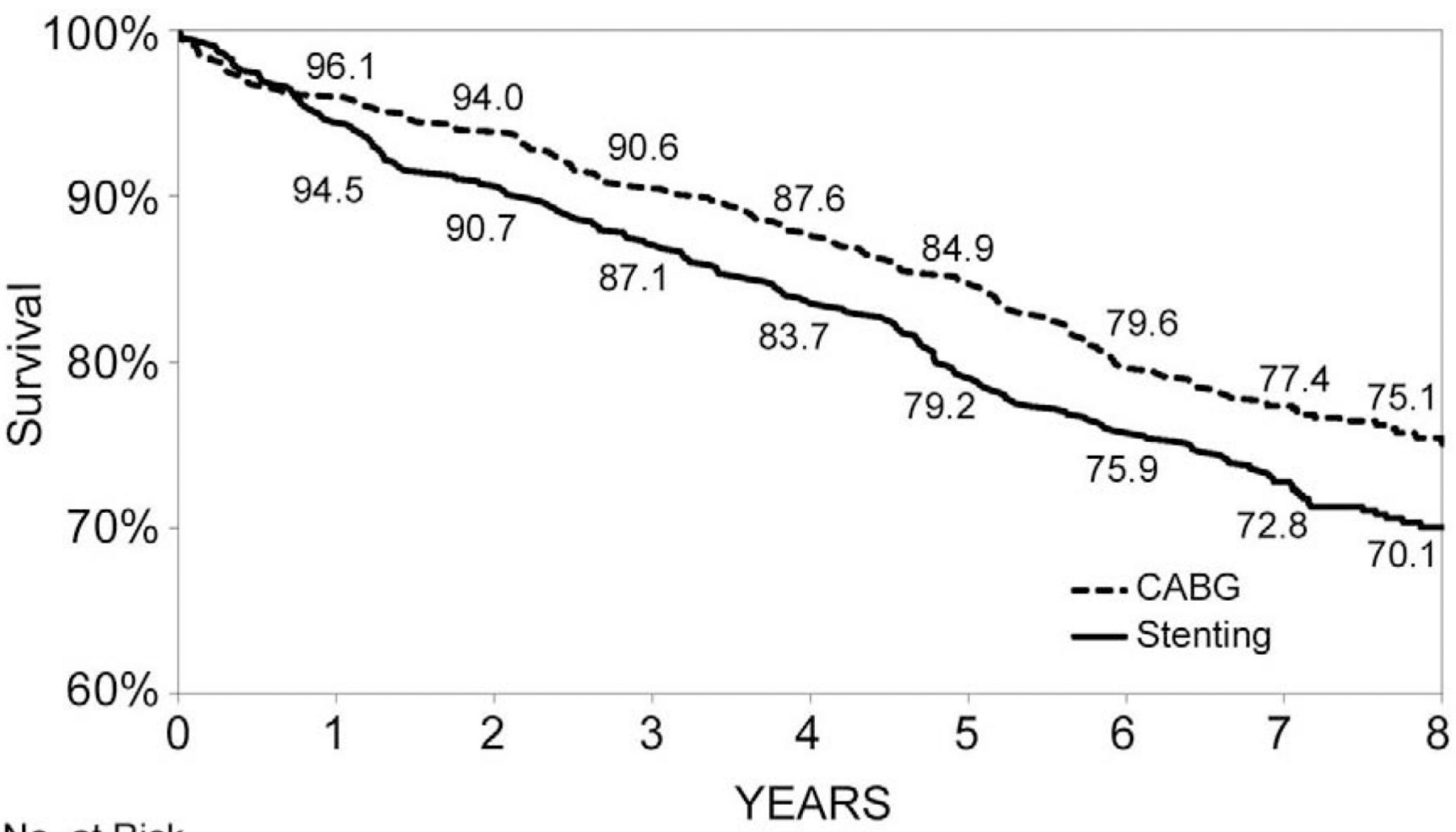

No. at Risk

\begin{tabular}{|c|c|c|c|c|c|c|c|c|c|}
\hline CABG & 614 & 590 & 577 & 556 & 538 & 521 & 489 & 475 & 218 \\
\hline Stenting 6 & 614 & 580 & 557 & 535 & 514 & 486 & 466 & 447 & 198 \\
\hline $\mathrm{P}$ Value & & 0.35 & 0.09 & 0.15 & 0.08 & 0.02 & 0.12 & 0.05 & 0.05 \\
\hline
\end{tabular}

Figure 1.

(Panels A-F). Kaplan-Meier survival curves for propensity matched CABG and stenting patients. 
Table 1

Risk factors in the 7,235 pairs of matched patients. ${ }^{*}$

\begin{tabular}{|c|c|c|}
\hline \multirow[b]{2}{*}{ Risk Factor } & \multicolumn{2}{|c|}{ No. $(\%)$} \\
\hline & CABG & Stenting \\
\hline Age (yr) & $65.6 \pm 10.7$ & $65.6 \pm 12.1$ \\
\hline \multicolumn{3}{|l|}{ Sex } \\
\hline Female & $2,165(29.9)$ & $2,172(30.0)$ \\
\hline Male & $5,070(70.1)$ & $5,063(70.0)$ \\
\hline \multicolumn{3}{|l|}{ Race/ethnicity } \\
\hline Non-Hispanic white & $6,035(83.4)$ & $6,018(83.2)$ \\
\hline Non-Hispanic black & $411(5.7)$ & $417(5.8)$ \\
\hline Hispanic & $452(6.3)$ & $465(6.4)$ \\
\hline Other & $337(4.7)$ & $335(4.6)$ \\
\hline Body surface area $\left(\mathrm{m}^{2}\right)$ & $2.0 \pm 0.2$ & $2.0 \pm 0.3$ \\
\hline \multicolumn{3}{|l|}{ Body mass index $\left(\mathrm{kg} / \mathrm{m}^{2}\right)$} \\
\hline$<18.5$ & $66(0.9)$ & $52(0.7)$ \\
\hline $18.5-24.99$ & $1,750(24.2)$ & $1,757(24.3)$ \\
\hline $25-29.99$ & $3,041(42.0)$ & $3,044(42.1)$ \\
\hline $30+$ & $2,378(32.9)$ & $2,382(32.9)$ \\
\hline \multicolumn{3}{|l|}{ No. of diseased vessels ${ }^{\dagger}$} \\
\hline 3, proximal LAD artery disease & $1,346(18.6)$ & $1,346(18.6)$ \\
\hline 3, nonproximal LAD artery disease & $1,392(19.2)$ & $1,392(19.2)$ \\
\hline 2, proximal LAD artery disease & $2,974(41.1)$ & $2,974(41.1)$ \\
\hline 2, nonproximal LAD artery disease & $909(12.6)$ & $909(12.6)$ \\
\hline 2, no LAD artery disease & $614(8.5)$ & $614(8.5)$ \\
\hline \multicolumn{3}{|l|}{ Ejection fraction } \\
\hline$<20 \%$ & $66(0.9)$ & $67(0.9)$ \\
\hline $20-29 \%$ & $300(4.2)$ & $307(4.2)$ \\
\hline $30-39 \%$ & $755(10.4)$ & $730(10.1)$ \\
\hline $40-49 \%$ & $1485(20.5)$ & 1492(20.6) \\
\hline$>=50 \%$ & $4393(60.7)$ & $4400(60.8)$ \\
\hline Missing & $236(3.3)$ & $239(3.3)$ \\
\hline \multicolumn{3}{|l|}{ Previous myocardial infarction } \\
\hline $1-7$ days prior & $1,439(19.9)$ & $1,448(20.0)$ \\
\hline $8-14$ days prior & $341(4.7)$ & $319(4.4)$ \\
\hline 15-20 days prior & $57(0.8)$ & $55(0.8)$ \\
\hline$>=21$ days prior & $1,484(20.5)$ & $1,480(20.5)$ \\
\hline No previous myocardial infarction & $3914(54.1)$ & $3933(54.4)$ \\
\hline \multicolumn{3}{|l|}{ Hemodynamic state } \\
\hline Stable & $7,189(99.4)$ & $7,189(99.4)$ \\
\hline Unstable & $37(0.5)$ & $39(0.5)$ \\
\hline Shock & $9(0.1)$ & $7(0.1)$ \\
\hline
\end{tabular}




\begin{tabular}{lcc}
\hline & \multicolumn{2}{c}{ No.(\%) } \\
\cline { 2 - 3 } Risk Factor & CABG & Stenting \\
\hline Cardiopulmonary resuscitation & $4(0.1)$ & $4(0.1)$ \\
Cerebrovascular disease & $770(10.6)$ & $766(10.6)$ \\
Peripheral arterial disease & $520(7.2)$ & $501(6.9)$ \\
Electrocardiographic evidence of left ventricular hypertrophy & $681(9.4)$ & $659(9.1)$ \\
Congestive heart failure & & \\
At current admission & $649(9.0)$ & $632(8.7)$ \\
Before current admission & $397(5.5)$ & $383(5.3)$ \\
$\quad$ None & $6,189(85.5)$ & $6,220(86.0)$ \\
Malignant ventricular arrhythmia & $120(1.7)$ & $113(1.6)$ \\
Chronic obstructive pulmonary disease & $613(8.5)$ & $617(8.5)$ \\
Diabetes & $2,101(29.0)$ & $2,074(28.7)$ \\
Renal Failure & & \\
Requiring dialysis & $89(1.2)$ & $88(1.2)$ \\
Creatinine $>2.5 \mathrm{mg} / \mathrm{dl}(220 \mu \mathrm{mol} /$ liter $)$ & $97(1.3)$ & $94(1.3)$ \\
No renal failure & $7,049(97.4)$ & $7,053(97.5)$ \\
\hline
\end{tabular}

* Plus-minus values are means \pm SD. CABG denotes coronary-artery bypass grafting, and LAD left anterior descending. P values were not significant $(>=0.19)$ for any comparisons

${ }^{\dagger}$ Diseased vessels were defined by the presence of stenosis of at least $70 \%$ 


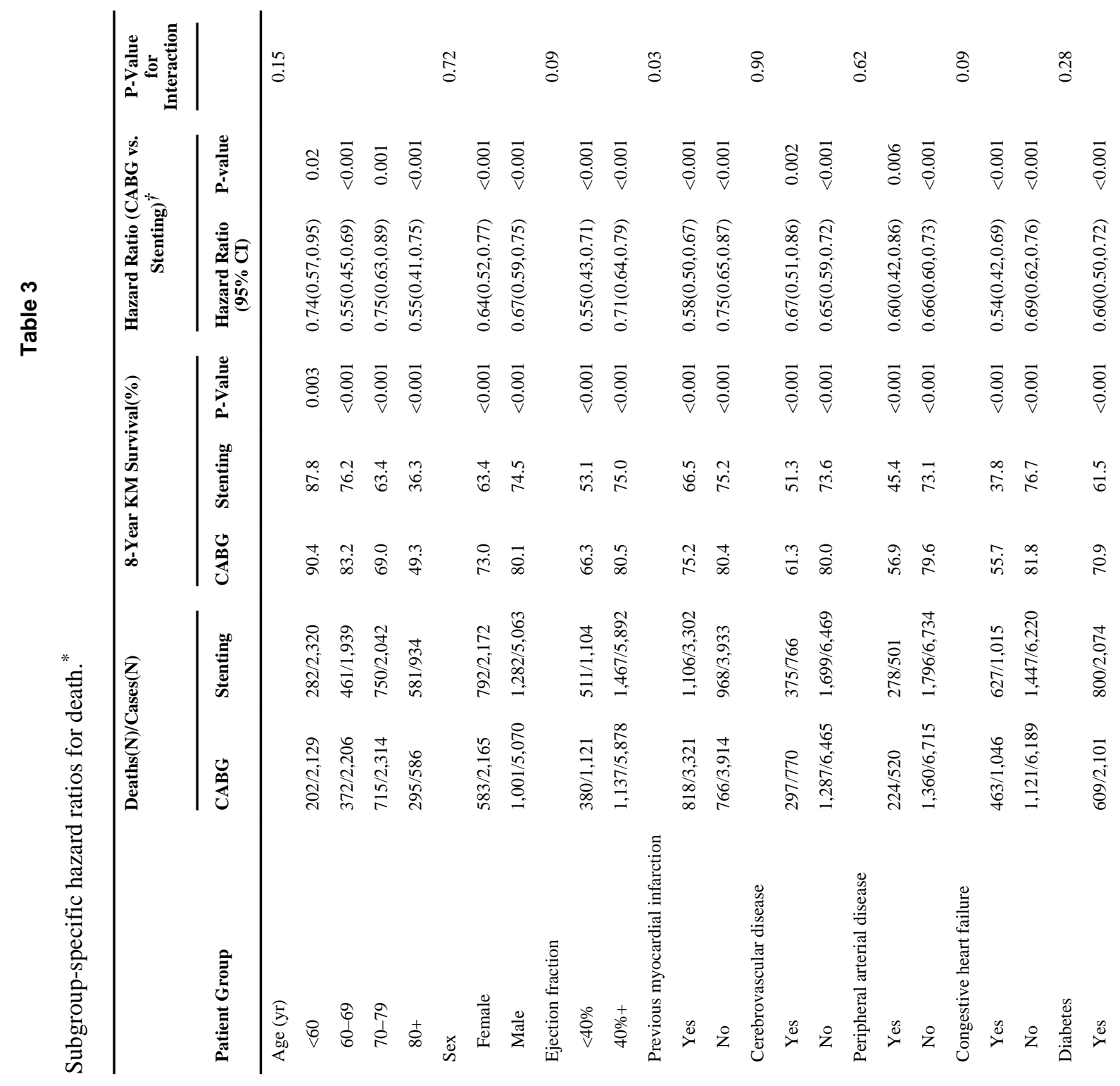




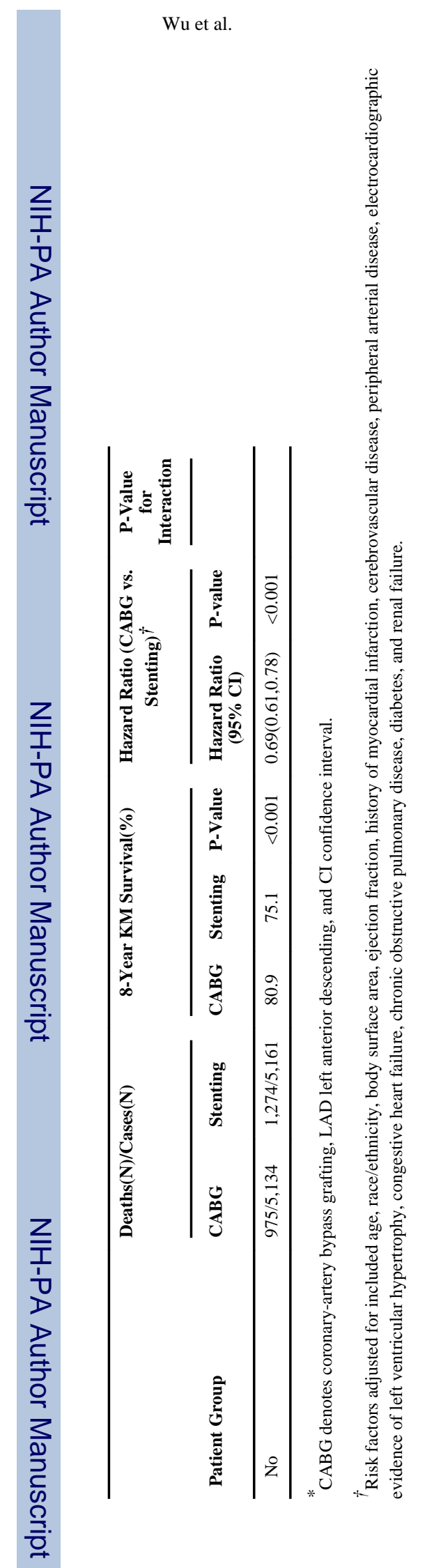

Ann Thorac Surg. Author manuscript; available in PMC 2012 December 1. 